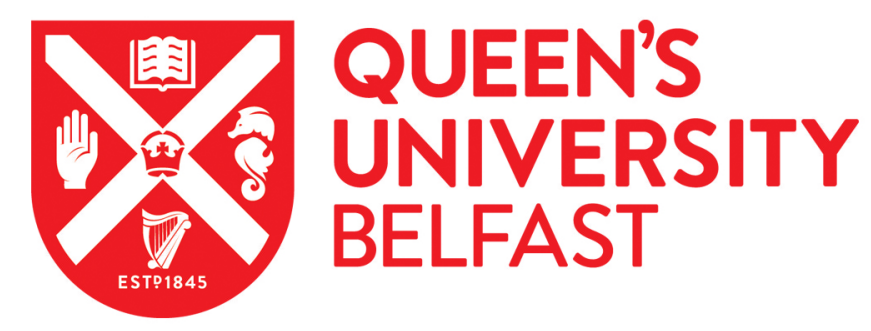

\title{
Renal failure parathyroidectomy - Is Pre-operative imaging worthwhile?
}

Spence, R. A. J., Patterson, T. J., Currie, P., Convie, L., Tong, L., Brown, T., \& Spence, R. A. J. (2018). Renal failure parathyroidectomy - Is Pre-operative imaging worthwhile? Surgeon-Journal of the royal colleges of surgeons of edinburgh and ireland. https://doi.org/10.1016/j.surge.2018.07.002

Published in:

Surgeon-Journal of the royal colleges of surgeons of edinburgh and ireland

Document Version:

Peer reviewed version

Queen's University Belfast - Research Portal:

Link to publication record in Queen's University Belfast Research Portal

Publisher rights

(c) 2018 Royal College of Surgeons of Edinburgh and Royal College of Surgeons in Ireland. Published by Elsevier Ltd. This manuscript is distributed under a Creative Commons Attribution-NonCommercial-NoDerivs License (https://creativecommons.org/licenses/by-nc-nd/4.0/), which permits distribution and reproduction for non-commercial purposes, provided the author and source are cited.

\section{General rights}

Copyright for the publications made accessible via the Queen's University Belfast Research Portal is retained by the author(s) and / or other copyright owners and it is a condition of accessing these publications that users recognise and abide by the legal requirements associated with these rights.

Take down policy

The Research Portal is Queen's institutional repository that provides access to Queen's research output. Every effort has been made to ensure that content in the Research Portal does not infringe any person's rights, or applicable UK laws. If you discover content in the Research Portal that you believe breaches copyright or violates any law, please contact openaccess@qub.ac.uk. 
Renal failure parathyroidectomy - Is pre-operative imaging worthwhile?

\section{ABSTRACT:}

Background: Tertiary hyperparathyroidism is a significant issue in renal failure patients and some require surgery to control their serum calcium. A number of imaging techniques are used to localise the position of the parathyroid glands prior to surgery. Currently, a combination of ultrasound and isotope preoperative localisation imaging is accepted as useful in parathyroid surgery for primary disease. However, the use of pre-operative imaging in parathyroid surgery in renal failure patients is uncertain. The role of pre-operative imaging of the parathyroid glands in patients with renal failure hyperparathyroidism was assessed with imaging outcomes compared to operative and pathological findings in two cohorts of patients undergoing parathyroid surgery - primary and tertiary.

Methods: All data were collected prospectively over a 10-year period (2003-2013) from the practice of a single surgeon. Patients were grouped into either primary hyperparathyroidism (49 patients) or tertiary hyperparathyroidism (41 patients). The majority, 63 of 90 (70\%) patients, underwent both ultrasound (US) and isotope (MIBI) pre-operative imaging. Pre-operative imaging was correlated with operative and pathological findings.

Findings: Comparison of the results of the two groups using ordinal regression analysis confirmed these imaging techniques are significantly more accurate in primary than tertiary parathyroid surgery $(p=0.022)$.

Conclusions: While accepted practice of pre-operative combined USS and MIBI imaging is essential in unilateral imaged-focused neck exploration for primary disease, these imaging techniques have a more limited use pre-operatively in renal failure parathyroidectomy.

KEY WORDS: Hyperparathyroidism, Primary, Tertiary, Imaging, MIBI, SPECT, Ultrasound

\section{INTRODUCTION:}

Hyperparathyroidism (HPT) describes a condition characterised by excessive secretion of parathyroid hormone (PTH), a polypeptide hormone produced by the parathyroid glands. PTH induces osteoclastic activity, reducing bone density, and increasing serum calcium. This increase in serum calcium can result in a wide range of clinical presentations, or alternatively patients may be asymptomatic and present incidentally. ${ }^{1}$ Primary hyperparathyroidism (PHPT) can be due to hyperplasia, but is more commonly ( $80 \%$ of patients) due to an adenoma of one or more of the parathyroid glands, with a single adenoma being the most common presentation. If symptomatic, surgical excision is considered as standard provided the patient is fit for surgery. ${ }^{2}$ In secondary hyperparathyroidism (SHPT), reduced activation of Vitamin D and phosphate retention resulting from declining renal function, trigger a decrease in calcium absorption and increased PTH secretion. ${ }^{3}$ In renal failure patients, transplantation has been demonstrated to biochemically reverse this condition. $^{3}$

It is after renal replacement therapy, either transplantation or dialysis, that tertiary hyperparathyroidism (THPT) presents. Parathyroid tissue which was previously driven by hypocalcaemia and hyperphosphataemia, fail to return to their normal state and continue their increased level of PTH secretion, resulting in hypercalcaemia. 3 This causes significant morbidity in renal transplant patients, with $17-50 \%$ of patients at 1 year displaying this condition. ${ }^{1}$ It increases the 
risk of graft dysfunction and loss, bone disease, and cardiovascular morbidity.2 Traditionally, like PHPT, THPT has been treated surgically. ${ }^{1}$

Medical management of THPT using calcimimetic agents has gained recognition. However, a 2017 systematic review concluded that surgical management of tertiary HPT had higher cure rates than medical therapy. Surgery is still the preferred therapy for the majority of patients. ${ }^{1}$ In primary disease, optimal surgical management is local and targeted, therefore accurate imaging for localisation is essential to reduce the need for bilateral neck exploration. ${ }^{4}$ Although the majority of parathyroid glands are distributed among the four usual anatomical positions (left inferior, left superior, right superior, and right inferior), intra-operative localisation can be challenging. ${ }^{5}$ It is reported that $6.5 \%-14 \%$ of the population have supernumerary glands, usually located in the thymus, with $16 \%-43 \%$ having one or more ectopic glands. ${ }^{5-7}$ The variability of individual gland location is due to their complex descent from the third and fourth pharyngeal pouches during foetal development. ${ }^{9}$

Pre-operative imaging is used to increase the accuracy of intra-operative location of parathyroid glands. ${ }^{10}$ Ultrasound (US), 99mTc-sestamibi isotope imaging (MIBI) and, less commonly, magnetic resonance imaging (MRI), and single-proton emission computed tomography (SPECT) imaging are used.11,12 US and MIBI are most popular, with US being readily available and MIBI regarded as having the highest sensitivity (57-82\%) of the two imaging modalities in PHPT. ${ }^{10,11}$ Most accept that for PHPT, a combination of USS and MIBI imaging is best, yet there is still debate of which localisation method is superior and in which combination for patients with THPT. The majority of studies examining the efficacy of pre-operative imaging in HPT report on patients with PHPT or SHPT. ${ }^{11-13}$

Studies exploring the efficacy of pre-operative imaging in THPT are fewer in number with small sample sizes. Published reports of the overall efficacy of MIBI imaging in THPT disease have demonstrated sensitivities of between $37 \%$ - 76\%.2,13 These studies have been small descriptive series which do not offer a comparative statistical analysis of their results.

\section{Aim}

The aim of this study is to add to the evidence determining the efficacy of pre-operative imaging in patients with tertiary hyperparathyroidism. A comparison with a concurrent series of primary HPT was performed.

\section{METHODS AND MATERIALS}

A non-randomised analysis of 90 consecutive patients with a pre-operative diagnosis of either primary HPT or tertiary HPT was conducted. The data were collected prospectively. These were from the practice of a single surgeon, in one centre, between July 2003 and May 2013. This centre is host to the regional renal transplant unit.

Demographic, clinical, and pathological data collected included patient age (years) at time of surgery, PHPT or THPT status, pre- and post-operative PTH and serum calcium levels, pre-operative imaging results (US, MIBI, and SPECT/CT), pathology (histology, number of glands, location), surgical findings, incidence of 'redo' surgery, mortality, and length of follow-up (months). All patients with PHPT underwent bilateral neck exploration.

PHPT was defined as a state of excessive PHT secretion in the presence of hypercalcaemia. THPT was 
defined as a state of excessive PHT secretion in the presence of hypercalcaemia, but in comparison to PHPT, this was after an extended period of SHPT. ${ }^{3} 99 \mathrm{mTc}$-Sestamibi imaging (MIBI) was conducted using a single-tracer, dual-phase method. Patients received $99 \mathrm{mTc}$-Sestamibi via intravenous (IV) route. Using a gamma camera, early and delayed views of the neck and thorax were obtained. A specialist nuclear radiologist reported all MIBI scans. Ultrasound (US) was performed by a specialist radiologist. Single-photon emission computed tomography / computed tomography (SPECT/CT) imaging was conducted using a multi-slice scanner. Patients received 99mTc- Sestamibi via intravenous (IV) route and, similarly to MIBI imaging, early and delayed views of the neck and thorax were obtained.

\section{Analysis}

Pre-operative imaging was compared to operative findings with respect to both number and location of glands. If there was full concordance between imaging and operative findings, this was classified as 'fully successful'. Some concordance with either US or isotope imaging and the operative findings led to a 'partially successful' classification, and a lack of correlation/concordance was recorded as 'unsuccessful'.

Ordinal regression was used for statistical analysis for comparing efficacy of imaging modalities and $P$ values were calculated with a two-tailed test.14 Significance was defined as a $p$ value of less than 0.05. IBM SPSS Version 15 was used for statistical analysis.15

\section{RESULTS}

The records of 90 patients who underwent parathyroidectomy over a period of 10 years (July $2003-$ May 2013) were analysed. 49 patients were diagnosed with PHPT and 41 patients with THPT. There were 60 males and 30 females.

Mean age at time of surgery was 52.8 years and median follow-up post-operatively was 69 months. There were no peri-operative, 30-day, or 90-day mortality; but 9 deaths occurred within the followup period unrelated to the surgery, with these patients all having THPT. The characteristics of the patients are displayed in Table 1.

In the combined patient group of both primary and tertiary, 63 of 90 (70.0\%) of patients underwent both US and MIBI pre-operative imaging. Overall, in this combined group, US imaging displays a nonsignificant trend towards increased accuracy over MIBI imaging $(p=0.474)$. If the imaging modalities (US and $\mathrm{MIBI}$ ) are combined, it is demonstrated that in PHPT disease they are significantly more effective than in THPT ( $p=0.022)$ in successfully locating glands.

In the PHPT group, 12 patients underwent SPECT/CT imaging. When compared to US imaging, there was a non-significant trend towards this imaging modality being more accurate $(p=0.242)$. MIBI imaging demonstrated a non-significant trend towards being less effective than SPECT/CT ( $p=$ 0.163 ), but the number of patients having SPECT/CT was small (12).

\section{Primary Group}

There were 49 patients in the PHPT group. After a median of 39 months follow-up there has been no 'redo' surgery or mortality. 31 (63.3\%) patients underwent ultrasound (US) pre-operatively, with 14 (45.2\%) failures of localisation, 1 (3.2\%) partial success, and 16 (51.6\%) fully successfully located when compared with operative and pathological findings. 42 (85.7\%) patients underwent MIBI preoperatively, with 15 (35.7\%) unsuccessful, 2 (4.8\%) partial successes, and 25 (59.5\%) fully successful. 
29 (59.1\%) patients underwent both US and MIBI imaging. In this subgroup when US and MIBI results were combined, there were $13(44.8 \%)$ full successes, $4(13.8 \%)$ partial successes, and 12 $(41.4 \%)$ patients were unsuccessfully imaged.

Unlike the THPT group, 12 (24.4\%) patients underwent pre-operative SPECT imaging. 1 (8.3\%) failure, 1 (8.3\%) partial success, and 10 (83.3\%) were fully successfully imaged. Biochemically corrected serum calcium fell in all 49 patients following surgery in the primary HPT group, with an average reduction of $0.56 \mathrm{mmol} / \mathrm{L}$. 15 (30.6\%) of the 49 patients had PTH levels taken after surgery, with a mean reduction of $80.7 \mathrm{pmol} / \mathrm{L}$. At 6-month surgical review, all patients in the PHPT group remained normocalcaemic and were discharged. No PHTP patients were re-referred with hypercalcaemia at the time of this analysis.

Pathologically, 53 glands were removed in the PHTP group. The authors were able to pair US imaging location data of 35 glands with operative location data, and compare 47 glands with operative location data with MIBI imaging. Overall, US was able to accurately locate 17 (48.6\%) glands and MIBI 26 (55.3\%) glands. There was one ectopic gland in this group, this was detected by MIBI imaging only. Pathological findings included $42(85.7 \%)$ patients had parathyroid adenomata, 6 (12.2\%) patients had hyperplasia, and there was 1 (2.0\%) case of atypia. There were no cases of parathyroid carcinoma.

\section{Tertiary Group}

There were 41 patients in the THPT group, 28 of these were currently undergoing haemodialysis and 13 had previously undergone renal transplantation. Three of the procedures were 're-do' surgeries. These were included for completion. After a median follow-up of 71 months, there had been 9 deaths (cardiovascular), none of which were peri-operative, 30-day, or 90-day. 34 (82.9\%) patients underwent ultrasound pre-operatively, with 12 (35.2\%) unsuccessful imaging attempts, 18 (52.9\%) partial successes, and $4(11.7 \%)$ fully successful. 35 (85.3\%) patients underwent MIBI pre8 operatively, with 18 (51.4\%) failures, 14 (40.0\%) partial successes, and 3 (8.6\%) fully successful. 34 (82.9\%) patients underwent both US and MIBI imaging. In this subgroup there were $3(8.8 \%)$ full successes, 24 (70.6\%) partial successes and 7 (20.6\%) were unsuccessful. No patients in this group underwent SPECT imaging. Table 2 displays the above results.

Biochemically corrected serum calcium fell in 39 (95.1\%) of patients following surgery, with an mean reduction of $0.43 \mathrm{mmol} / \mathrm{l} .33(80.5 \%)$ of the 41 patients had PTH levels taken after surgery, with an mean reduction of $1510.2 \mathrm{pmol} / \mathrm{l}$. Corrected serum calcium level prior to surgery was significantly correlated with imaging success in tertiary disease $(p=0.003)$.

Pathologically, 144 glands were excised in the THTP group. 40 (97.5\%) patients demonstrated hyperplasia and there was 1 (2.5\%) case of adenoma. The authors were able to pair US imaging location data of 121 glands with operative location data and 120 glands with MIBI imaging data. US was able to accurately locate 37 (30.6\%) glands and MIBI 21 (17.5\%). There were 2 ectopic glands resected in this group, one of which was detected by MIBI.

When comparing the haemodialysis and transplant patient groups, imaging in the transplant group demonstrated a non-significant decreased accuracy in gland location $(p=0.252)$. PTH level after operative intervention, but not before, was significantly correlated with imaging success in tertiary disease $(p=0.021)$. 


\section{DISCUSSION:}

When ultrasound and MIBI imaging results were analysed using ordinal regression analysis, it was demonstrated these imaging techniques in combination are significantly more accurate in primary than tertiary parathyroid surgery $(p=0.022)$. Additionally, it was demonstrated that pre-operative serum corrected calcium is positively correlated with imaging success in tertiary HPT $(p=0.003)$, this correlation has not to the authors' knowledge been reported before in the literature.

While the accuracy in pre-operative imaging is clearly less in THPT compared to PHTP in this study, there may still may be a place for such investigations to provide a surgical road map in some of these patients - particularly those undergoing difficult 're-do' surgery. The surgeon, however, must be aware of the limitations of imaging in patients with THPT. Imaging in the renal parathyroid patient before surgery, may be particularly helpful in those individuals who have an ectopic gland as a cause for persistent or recurrent hyperparathyroidism; for example, three patients in our study cohort had ectopic mediastinal disease, two of which were correctly identified using MIBI imaging. The efficacy of SPECT imaging when compared with US and MIBI was also analysed in the PHPT group. This demonstrated a non-significant trend $(p=0.242$ and $p=0.163)$ towards superiority over both US and MIBI imaging respectively. However, the small numbers in the group (12 patients), enables only limited conclusions to be drawn from these results.

The efficacy of pre-operative imaging in THPT disease has been debated in the literature. The results of this study are indicative of the existing literature in the field. A non-systematic literature review found six studies, which are described below. These had a median sample size of 32 THPT patients (range $9-122$ ). However, they often combined SHPT and THPT patients together under the grouping of 'renal hyperparathyroidism'. Another factor, which limits comparison, is how imaging efficacy was presented statistically. Some presented results as sensitivity and specificity. The authors of these studies defined false positives as an area of distinct MIBI accumulation in an area which did not coincide with an abnormal gland at time of surgery; false negatives were defined as a lack of $\mathrm{MIBI}$ accumulation in an area where an abnormal gland was found at time of surgery. ${ }^{3,16}$ The authors of this paper decided not to summarise results of this study as sensitivity or specificity as it produced ordinal, not dichotomous, outcomes (fully successful, partially successful and unsuccessful). Therefore, to calculate sensitivity and specificity, it would mean moving the 'partial success' into one of the other groups, creating dichotomous variables. This would use less information than what we have obtained, concluding that sensitivity and specificity cannot be appropriately calculated. The characteristics of the six studies previously reported in this area are summarised below in Table 3 . The datasets and results are heterogeneous in nature, some presented their results as the total number of resected glands, and others presented the number of resected ectopic gland successful pre-operatively imaged. ${ }^{12,18-20}$

The only study examining sensitivity in a population comprising solely of THPT patients was that of Loftus' series of twenty-one patients with THPT. ${ }^{4}$ MIBI scan was demonstrated to have a sensitivity of $76 \%$ for locating parathyroid tissue, with 16 true positive MIBI results and 5 false negatives. Karipineni failed to provide THPT specific data, as their population also included SHPT, iodine induced HPT, and MEN syndrome induced HPT patients. ${ }^{16}$ Overall, they demonstrated sensitivity, for ectopic glands only, of $36 \%$ for MIBI and $7 \%$ for US.

These heterogeneous data do not allow us to draw direct comparisons with our study. An interest to the surgeon is potential ectopic parathyroid tissue which may be missed without pre-operative imaging. Our study described 2 of 3 ectopic glands localised accurately using MIBI as discussed above. Lai et $a l^{18}$ combined THPT and SHPT groups. They examined MIBI and US efficacy for both for 
ectopic and normal anatomical position glands. It found that 101 of 276 (36.6\%), of pathologically confirmed parathyroid glands were located using MIBI imaging. 99 (35.9\%) glands were located using US. For the THPT patients in this study, US was able to accurately locate 37 (31\%) glands and MIBI 21 (18\%). De Andrade ${ }^{19}$ had the largest population (122 THPT patients) of any study examining imaging in THPT to date - SHPT and THTP data were combined. In this study, $14 \%$ of parathyroid glands were located in an ectopic position, with US locating 18 (19.8\%) and MIBI locating 24 (26.4\%) glands accurately. Kebebew' $\mathrm{s}^{17}$ series of 34 THPT patients demonstrated that neither US (14 patients), MIBI (15 patients), or MRI (7 patients) preoperatively located any ectopic tissue. Alkhalili's ${ }^{20}$ retrospective series also combined THPT and SHPT patients, demonstrating when the results of pre-operative US and MIBI were combined, $50 \%$ of ectopic glands were missed. The statistical analysis of this study permitted the authors to explore the clinical question of the efficacy of pre-operative imaging in THPT. ${ }^{14}$ It did not sacrifice analytical rigor by dichotomising patient level outcomes into 'success' and 'failure' categories.

\section{Clinical implication and future research}

The results of this study report that the accuracy of pre-operative imaging in THPT is lower when compared to PHPT. However, the withdrawal of MIBI and US from pre-operative assessment of THPT patients may lead to a reduction in the number of parathyroid glands being successfully located operatively, particularly ectopic glands. While at the time of the series, all patients with PHPT underwent bilateral neck exploration, it is accepted that in future series, the surgical approach will be an unilateral image-focused procedure. There may be a role for the use of other localisation studies, namely SPECT/CT, to be performed pre-operatively. Future research should concentrate on producing larger THPT specific datasets, which will allow for comparison, systematic review and meta-analysis.

\section{Limitations}

Our study size compared favourably with other studies in this area, which have a median of 32 THPT patients. This study is the largest with a distinct THPT sample group, coupled with a comparative analysis between the efficacy of imaging in PHPT and THPT. We accept the patient numbers in the PHPT group are small, however, the THPT group size compares favourably with other studies in the literature.

This study reflects the practice of a single experienced surgeon which has its advantages and disadvantages. It benefits from consistency (with lack of variability with multiple surgeons), moreover the data are obtained from a single centre. US imaging is operator dependant and in this series there were a number of US radiologists. To improve the statistical rigor of this study we continue to record prospectively the imaging data of these complex renal patients. We continue to image our renal patients prior to surgery as we gather further data - with the caveat that our study demonstrates current imaging is less useful in these complex patients compared with those with primary hyperparathyroidism.

\section{CONCLUSION:}

Accepted practice of pre-operative combined USS and MIBI imaging is essential in unilateral, image focused neck exploration for PHTP disease. However, we believe that these imaging techniques have more limited use pre-operatively in renal failure patients presenting with THTP, although they may still be useful in the patient undergoing re-exploration, and in those who may have ectopic glands. 
Acknowledgements: We would like to thank Dr Michael Stevenson (Queen's University, Belfast) for the assistance with statistical analysis.

Source of Financial Support: This research did not receive any specific grant from funding agencies in the public, commercial, or not-for-profit sectors.

\section{REFERENCES:}

1. Dulfer RR, Franssen GJH, Hesselink DA, Hoorn EJ, van Eijck CHJ, van Ginhoven TM. Systematic review of surgical and medical treatment for tertiary hyperparathyroidism. Br J Surg. 2017;104(7):804-13.

2. Bilezikian JP, Brandi ML, Eastell R, Silverberg SK, Edelsman R, Marcocci C, et al. Guidelines for the management of aysmptomatic primary hyperparathyroidism: summary statement from the Fourth International Workshop. J Clin Endocrinol Metab. 2014;99(10):3561-3569

3. Evenepoel P. Recovery versus persistence of disordered mineral metabolism in kidney transplant recipients. Semin Nephrol; 2013(33):191-203

4. Loftus KA, Anderson S, Mulloy AL, Terris DJ. Value of sestamibi scans in tertiary hyperparathyroidism. Laryngoscope. 2007;117(12):2135-8.

5. LoPinto M, Rubio GA, Khan ZF, Vaghaiwalla TM, Farra JC, Lew JI. Location of abnormal parathyroid glands: lessons from 810 parathyroidectomies. J Surg Res. 2017;Jan;207:22-6.

6. Phitayakorn R, McHenry CR. Incidence and location of ectopic abnormal parathyroid glands. Am J Surg. 2006;191(3):418-23.

7. Numano M, Tominaga Y, Uchida K, Orihara A, Tanaka Y, Takagi H. Surgical Significance of Supernumerary Parathyroid Glands in Renal Hyperparathyroidism. World J Surg. 1998;22(10):1098-103.

8. Schneider R, Waldmann J, Ramaswamy A, Fernández ED, Bartsch DK, Schlosser K. Frequency of Ectopic and Supernumerary Intrathymic Parathyroid Glands in Patients with Renal Hyperparathyroidism: Analysis of 461 Patients Undergoing Initial Parathyroidectomy with Bilateral Cervical Thymectomy. World J Surg. 2011;35(6):1260-5.

9. Scharpf J, Kyriazidis N, Kamani D, Randolph G. Anatomy and embryology of the parathyroid gland. Oper Tech Otolaryngol Neck Surg. 2016;27(3):117-21.

10. Kobylecka M, Płazińska MT, Chudziński W, Fronczewska-Wieniawska K, Mączewska J, Bajera A, et al. Comparison of scintigraphy and ultrasound imaging in patients with primary, secondary and tertiary hyperparathyroidism - own experience. J Ultrason. 2017;17(17):1722.

11. Piciucchi S, Barone D, Gavelli G, Dubini A, Oboldi D, Matteuci F. Primary hyperparathyroidism: imaging to pathology. J Clin Imaging Sci. 2012;2:59.

12. Öksüz MÖ, Dittmann $H$, Wicke $C$, Müssig K, Bares R, Pfannenberg $C$, et al. Accuracy of parathyroid imaging: A comparison of planar scintigraphy, SPECT, SPECT-CT, and C-11 methionine PET for the detection of parathyroid adenomas and glandular hyperplasia. Diagnostic Interv Radiol. 2011;17(4):297-307.

13. Lai ECH, Ching ASC, Leong HT. Secondary and tertiary hyperparathyroidism: Role of preoperative localization. ANZ J Surg. 2007;77(10):880-2.

14. Bender R, Grouven U. Ordinal logistic regression in medical research. J R Coll Physicians Lond. 1997;31(5):546-51.

15. IBM Corp. Released 2013. IBM SPSS Statistics for Windows, Version 22.0. Armonk, NY: IBM Corp. 
16. Karipineni F, Sahli Z, Somervell H, Mathur A, Prescott JD, Tufano RP, et al. Are preoperative sestamibi scans useful for identifying ectopic parathyroid glands in patients with expected multigland parathyroid disease? Surgery. 2018;163(1):35-41.

17. Kebebew E, Duh QY, Clark OH. Tertiary Hyperparathyroidism. Arch Surg. 2004;139(9):974.

18. Lai ECH, Ching ASC, Leong HT. Secondary and tertiary hyperparathyroidism: Role of preoperative localization. ANZ J Surg. 2007;77(10):880-2.

19. de Andrade JSC, Mangussi-Gomes JP, da Rocha LA, Ohe MN, Rosano M, das Neves MC, et al. Localization of ectopic and supernumerary parathyroid glands in patients with secondary and tertiary hyperparathyroidism: surgical description and correlation with preoperative ultrasonography and Tc99m-Sestamibi scintigraphy. Braz J Otorhinolaryngol. 2014;80(1):2934.

20. Alkhalili E, Tasci Y, Aksoy E, Aliyev S, Soundararajan S, Taskin E, et. al. The Utility of Neck Ultrasound and Sestamibi Scans in Patients with Secondary and Tertiary Hyperparathyroidism. World J Surg. 2015;39(3):702-705 
Table 1.

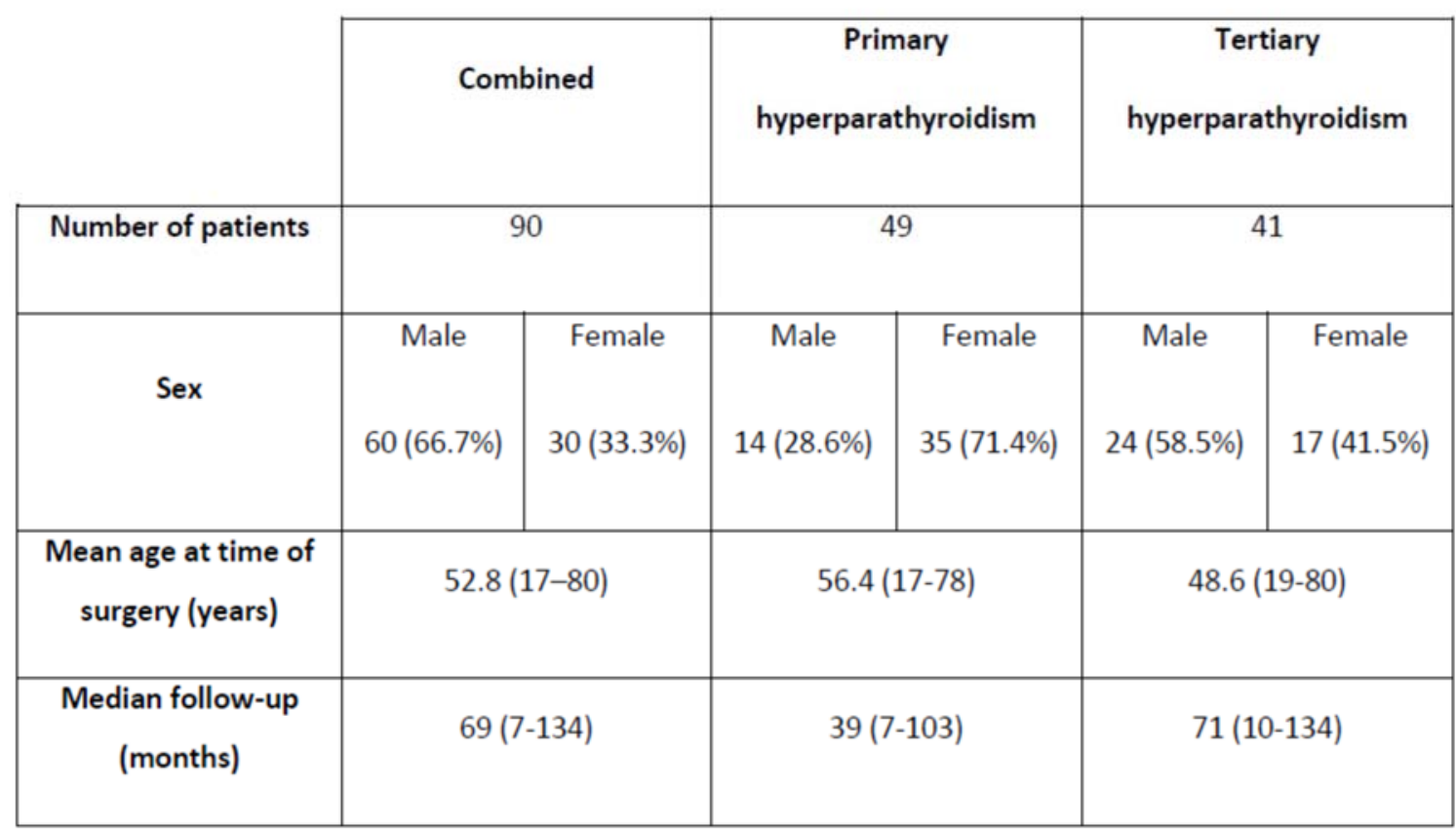

Table 1. Patient demographics, median follow-up. 
Table 2.

\begin{tabular}{|c|c|c|c|c|c|}
\hline & $\begin{array}{l}\text { Imaging / } \\
\text { Operative } \\
\text { Findings } \\
\text { Correlation }\end{array}$ & US Imaging & $\begin{array}{c}\text { MIBI } \\
\text { Imaging }\end{array}$ & $\begin{array}{l}\text { US / MIBI } \\
\text { Imaging }\end{array}$ & $\begin{array}{c}\text { SPECT / CT } \\
\text { Imaging }\end{array}$ \\
\hline \multirow{4}{*}{$\begin{array}{c}\text { Primary HPT } \\
\text { Group } \\
49 \text { Patients }\end{array}$} & Total in Group & $31(63.3 \%)$ & $42(85.7 \%)$ & $29(59.1 \%)$ & $12(24.4 \%)$ \\
\hline & Fully Successful & $16(51.6 \%)$ & $25(59.5 \%)$ & $13(44.8 \%)$ & $10(83.4 \%)$ \\
\hline & $\begin{array}{c}\text { Partially } \\
\text { Successful }\end{array}$ & $1(3.2 \%)$ & $2(4.8 \%)$ & $4(13.8 \%)$ & $1(8.3 \%)$ \\
\hline & Unsuccessful & $14(45.2 \%)$ & $15(35.7 \%)$ & $12(41.4 \%)$ & $1(8.3 \%)$ \\
\hline \multirow{4}{*}{ Tertiary HPT } & Total in Group & $34(82.9 \%)$ & $35(85.3 \%)$ & $34(82.9 \%)$ & \multirow{4}{*}{$\begin{array}{l}\text { conducted in } \\
\text { this group }\end{array}$} \\
\hline & Fully Successful & $4(11.8 \%)$ & $3(8.6 \%)$ & $3(8.8 \%)$ & \\
\hline & $\begin{array}{c}\text { Partially } \\
\text { Successful }\end{array}$ & $18(52.9 \%)$ & $14(40.0 \%)$ & $24(70.6 \%)$ & \\
\hline & Unsuccessful & $12(35.3 \%)$ & $18(51.4 \%)$ & $7(20.6 \%)$ & \\
\hline
\end{tabular}

Table 2. Imaging results from the PHPT and THPT groups. 
Table 3.

\begin{tabular}{|c|c|c|c|c|c|}
\hline Author & Year & $\begin{array}{l}\text { Number of } \\
\text { patients }\end{array}$ & Population & $\begin{array}{l}\text { Number (\%) of } \\
\text { patients with } \\
\text { ectopic glands }\end{array}$ & Study Results: \\
\hline Kebebew ${ }^{17}$ & 2004 & 34 & THPT & $11(32 \%)$ & $\begin{array}{l}\text { MIBI, US and MRI all detected no } \\
\text { ectopic tissue. }\end{array}$ \\
\hline $\operatorname{Lai}^{18}$ & 2007 & $\begin{array}{c}73 \\
\text { (9 THPT) }\end{array}$ & THPT and SHPT & Not specified & $\begin{array}{l}\text { MIBI located } 101 \text { of } 276 \text { glands (36.6\%). } \\
\text { US located } 99 \text { of } 276 \text { glands ( } 35.9 \%) \text {. }\end{array}$ \\
\hline Loftus $^{4}$ & 2007 & 21 & THPT & $9(43 \%)$ & $\begin{array}{l}\text { MIBI sensitivity was } 76 \% \text { for detecting } \\
\text { parathyroid tissue. }\end{array}$ \\
\hline $\begin{array}{c}\text { De } \\
\text { Andrade }^{19}\end{array}$ & 2014 & $\begin{array}{c}166 \\
\text { (122 THPT) }\end{array}$ & THPT and SHPT & $\begin{array}{l}91(14 \%) \\
\text { (Out of } 577 \text { total } \\
\text { glands) }\end{array}$ & $\begin{array}{l}\text { MIBI located } 24 \text { of } 91 \text { ectopic glands } \\
\qquad(26.4 \%) \text {. } \\
\text { US located } 18 \text { of } 91 \text { ectopic glands } \\
(19.8 \%) .\end{array}$ \\
\hline Alkhaliki $^{20}$ & 2015 & $\begin{array}{c}103 \\
\text { (68 THPT) }\end{array}$ & THPT and SHPT & $41(40 \%)$ & $\begin{array}{l}\text { US and MIBI combined located } 50 \% \text { of } \\
\text { ectopic glands. }\end{array}$ \\
\hline Karipineni ${ }^{16}$ & 2017 & $\begin{array}{c}149 \\
\text { (31 THPT) }\end{array}$ & $\begin{array}{l}\text { SHPT, THPT, } \\
\text { iodine induced } \\
\text { HTP and HPT } \\
\text { due to MEN } \\
\text { syndrome. }\end{array}$ & $64(43 \%)$ & $\begin{array}{l}\text { MIBI sensitivity of } 36 \% \text { for ectopic } \\
\text { gland detection. } \\
\text { US sensitivity } 7 \% \text { for ectopic gland } \\
\text { detection. }\end{array}$ \\
\hline
\end{tabular}

Table 3. Overview of previous THPT imaging studies including population dataset, ectopic glands, and results 